\title{
Apparent Surface Free Energy of Polymer/Paper Composite Material Treated by Air Plasma
}

\author{
Konrad Terpiłowski \\ Department of Physical Chemistry, Interfacial Phenomena, Faculty of Chemistry, Maria Curie-Sklodowska University, \\ 20-031 Lublin, Poland \\ Correspondence should be addressed to Konrad Terpiłowski; terpil@poczta.umcs.lublin.pl
}

Received 30 January 2017; Accepted 2 April 2017; Published 27 April 2017

Academic Editor: Stefano Turri

Copyright (C) 2017 Konrad Terpiłowski. This is an open access article distributed under the Creative Commons Attribution License, which permits unrestricted use, distribution, and reproduction in any medium, provided the original work is properly cited.

Surface plasma treatment consists in changes of surface properties without changing internal properties. In this paper composite polymer/paper material is used for production of packaging in cosmetic industry. There are problems with bonding this material at the time of packaging production due to its properties. Composite surface was treated by air plasma for 1, 10, 20, and 30 s. The advancing and receding contact angles of water, formamide, and diiodomethane were measured using both treated and untreated samples. Apparent surface free energy was estimated using the hysteresis (CAH) and Van Oss, Good, Chaudhury approaches (LWAB). Surface roughness was investigated using optical profilometry and identification of after plasma treatment emerging chemical groups was made by means of the XPS (X-ray photoelectron spectroscopy) technique. After plasma treatment the values of contact angles decreased which is particularly evident for polar liquids. Apparent surface free energy increased compared to that of untreated samples. Changes of energy value are due to the electron-donor parameter of energy. This parameter increases as a result of adding polar groups at the time of surface plasma activation. Changes of surface properties are combination of increase of polar chemical functional groups, increase on the surface, and surface roughness increase.

\section{Introduction}

Surface plasma treatment is an interesting way to change surface properties of many kinds of material: metals [1-3], polymers [4-6], and wood [7-9]. Plasma treatment leads to surface property changes due to the formation of functional groups on the surface. Character of the formed groups is determined by the gas used for plasma production [10]. Reduced costs and development of equipment have made a new era in the plasma technique application. In the case of printing industry there are several industrial problems, for example, with composite production and printing process. The main problem is the electrical charge accumulating on freshly made sheets and increasing its adherence. It is virtually impossible to download them from the stack to print. The other problem is the apparent surface free energy (surface tension of solids, industrial term), which should be higher than $38 \mathrm{~mJ} / \mathrm{m}^{2}$; if not it is impossible to print something by the offset technique using these materials. Tadmor et al. [11] mentioned that in the case of water adhesion to solids with work of separation lower than $30 \mathrm{~mJ} / \mathrm{m}^{2}$ no drop is left behind. When it is higher than $30 \mathrm{~mJ} / \mathrm{m}^{2}$ there is a drop left behind. It seems that there exists some critical work of adhesion responsible for various phenomena and dependent on surface properties and liquid surface tension. Next problem is bonding of these materials, for instance, when packaging for cosmetics is produced. Traditionally the top polyester layer is removed and/or surface of welt is roughened. However, special glue should be used and there is always a lot of waste. For a couple of years we have been collaborating with El-Press Company from Lublin (Poland) producing polymer/paper composite materials.

In scientific literature it is possible to find some research in case of polyester; however, our material is slightly different because it is composite polymer glue to papers support. Investigations of plasma treatment of polystyrene were carried out by Molina et al. [12] using polyester which is usually applied in textile glossary and treated with atmospheric plasma of the power of $1000 \mathrm{~W}$ along with different dosages, such as 500 to $7500 \mathrm{~W}$ min $\mathrm{m}^{-2}$. There was a textile polyester material 


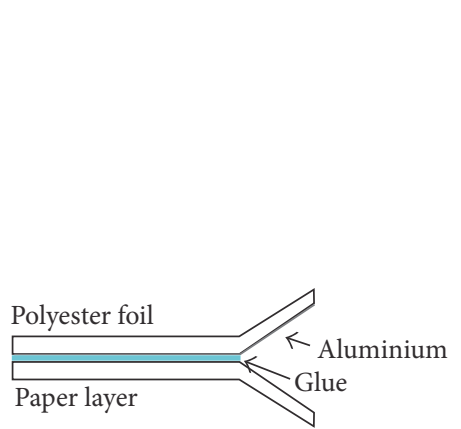

(a)

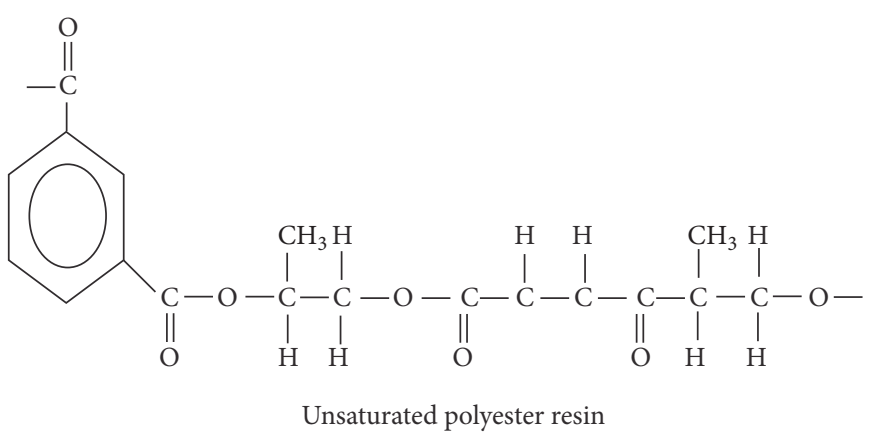

(b)

Figure 1: (a) Polyester used as top layer in composite production. (b) Schematic picture of the examined material.

used (woven material) with wettability described by the Cassie-Baxter model [13] and due to that the values of water contact angles in the model were higher than those measured in this paper. Moreover, after plasma treatment the value of the water contact angle decreased.

Molina et al. [12] also mentioned that the increase of energy is due to polar group formation on the surface and plasma activation with a higher dosage did increase the functional groups but not the surface roughness. Plasma treatment removes surface contamination which can help with surface unification. Zhao et al. [14] determined the effect of washing plasma treated samples in distilled water for the apparent surface free energy of polystyrene plate treated by the radio frequency atmospheric pressure plasma. The water contact angle on the untreated sample was about $85^{\circ}$. Just after $0.5 \mathrm{~s}$ of plasma treatment water contact angle decreased to about $20^{\circ}$. Lengthening of plasma treatment did not induce significant changes of water contact angle value [14]. They showed changes of apparent surface free energy value as a function of the plasma treatment time. When plasma treatment was done for a short time the total value and the polar component of the energy increased sharply and then stabilized.

The main aim of these investigations was to learn how the air plasma treatment influences the surface properties of composite polymer/paper materials and whether it can find practical application and also to check new way of wettability description. In that case it is hard to be based on literature because we have a lot of kinds of polyesters and many types of plasma modifications.

\section{Experimental}

2.1. Surface Characterization. $2 \times 2 \mathrm{~cm}$ plates (El-Press http:// el-press.pl/pl/) were cut out from a larger one, obtained from the freshly produced material. The scheme of the tested material is shown in Figure 1(a). The top layer of the test material is polyester foil ( $12 \mu \mathrm{m}$ thick), from the bottom there is a layer of aluminium, and the next is a layer of paper. Both layers are stuck by the Jowat (http://www.jowat.com.pl/pl/) company glue.
2.2. FT-IR. The FT-IR spectra of untreated composite plate were recorded on the Nicolet $8700 \mathrm{~A}$ research-grade FT-IR spectrometer using the Attenuated Total Reflectance (ATR) mode. The spectral range was $4000-400 \mathrm{~cm}^{-1}$; the resolution was set to $4 \mathrm{~cm}^{-1}$.

2.3. Surface Plasma Treatment. Plasma activation was performed in a low pressure plasma system Pico from Diener Electronic, Germany. The plates were placed on the sample stage and the system was led to a pressure of $0.2 \mathrm{mbar}$. Then the gas flow (air) was set at $22 \mathrm{sccm}$ (standard cubic centimeters per minute). The plates were treated with the plasma power $160 \mathrm{~V}$ (400 V max) for 1, 10, 20, and 30 seconds. In order to remove the gaseous products, the chamber was purged with air for $10 \mathrm{~s}$. To open the chamber it was necessary for the atmospheric pressure to be placed inside.

2.4. Contact Angle Measurements. Digidrop GBX Contact Angle Meter (France) equipped with a video-camera system and computer software was used for the contact angle measurements by the sessile drop method. The advancing contact angles of water (Milli-Q) and two other probe liquids, diiodomethane (99\% Sigma-Aldrich Germany) and formamide (POCH SA), were measured after softly settling $6 \mu \mathrm{L}$ droplet on the surface. Then after delicate sucking of $2 \mu \mathrm{L}$ liquid from the droplet into the syringe, the receding contact angle was measured. The contact angles of probe liquids were measured at $20 \pm 1^{\circ} \mathrm{C}$ in a closed chamber. Three composite plates were produced and the contact angles of 10 water droplets on each film were measured. Thus, the mean values of 30 contact angles are plotted in the figures.

2.5. Determination of Apparent Free Energy. If we agree that the advancing contact angle is the largest possible contact angle on the particular surface and the receding one is the lowest, the equilibrium contact angle is somewhere between them. To calculate equilibrium contact angle Tadmor $[15,16]$ theory was used. Tadmor proposed calculation of equilibrium 
contact angle [17-19]; (1a), (1b), and (1c) were used for this purpose.

$$
\begin{aligned}
& \Gamma_{a} \equiv\left(\frac{\sin ^{3} \theta_{a}}{\left(2-3 \cos \theta_{a}+\cos ^{3} \theta_{a}\right)}\right)^{1 / 3} ; \\
& \Gamma_{r} \equiv\left(\frac{\sin ^{3} \theta_{r}}{\left(2-3 \cos \theta_{r}+\cos ^{3} \theta_{r}\right)}\right)^{1 / 3} ; \\
& \theta_{0}=\arccos \left(\frac{\Gamma_{a} \cos \theta_{a}+\Gamma_{r} \cos \theta_{r}}{\Gamma_{a}+\Gamma_{r}}\right),
\end{aligned}
$$

where $\Gamma_{a}$ is the advancing angle weight coefficient [20] and $\Gamma_{r}$ is the receding angle weight coefficient.

In this paper two approaches are applied. The first one is the approach proposed by van Oss et al. (LWAB) [21-23], where the energy is determined from the advancing contact angles of one apolar and two polar liquids.

$$
\begin{aligned}
W_{A} & =\gamma_{l}\left(1+\cos \theta_{\mathrm{eq}}\right) \\
& =2 \sqrt{\gamma_{s}^{\mathrm{LW}} \gamma_{l}^{\mathrm{LW}}}+2 \sqrt{\gamma_{s}^{+} \gamma_{l}^{-}}+2 \sqrt{\gamma_{s}^{-} \gamma_{l}^{+}},
\end{aligned}
$$

where $W_{A}$ is work of adhesion, $\gamma_{l}$ is liquid surface tension, $\theta_{\text {eq }}$ is contact angle (equilibrium), $\gamma_{s / l}^{\mathrm{LW}}$ is solid and liquid apolar Lifshitz-van der Waals interactions, $\gamma_{s / l}^{+}$is solid and liquid electron acceptor parameter of surface free energy, and $\gamma_{s / l}^{-}$ is solid and liquid electron donor parameter of surface free energy.

However, using this approach in the case of hydrophobic surfaces often gives negative values of the square root for polar parameter, usually the electron-acceptor ones. Such result does not make any sense from a physicochemical point of view and then the total surface free energy is actually expressed by the dispersion component only.

Another approach proposed by Chibowski [24-26] is based on the contact angle hysteresis (CAH).

$$
\gamma_{s}=\frac{\gamma_{l}\left(1+\cos \theta_{a}\right)^{2}}{2+\cos \theta_{r}+\cos \theta_{a}},
$$

where $\gamma_{s}$ is apparent surface free energy, $\gamma_{l}$ is liquid surface tension, $\theta_{a}$ is advancing contact angle, and $\theta_{r}$ is receding contact angle.

The apparent surface free energy is calculated from (3) using the advancing and receding contact angles and the liquid surface tension. The calculated free energy value depends somewhat on the physicochemical properties of the liquid used. When the equilibrium contact angles were used for calculation of apparent surface free energy, (3) transforms into

$$
\gamma_{s}=\frac{\gamma_{l}}{2}\left(1+\cos \theta_{\mathrm{Eq}}\right)
$$

where $\gamma_{l}$ is liquid surface tension and $\theta_{\mathrm{Eq}}$ is equilibrium contact angle.

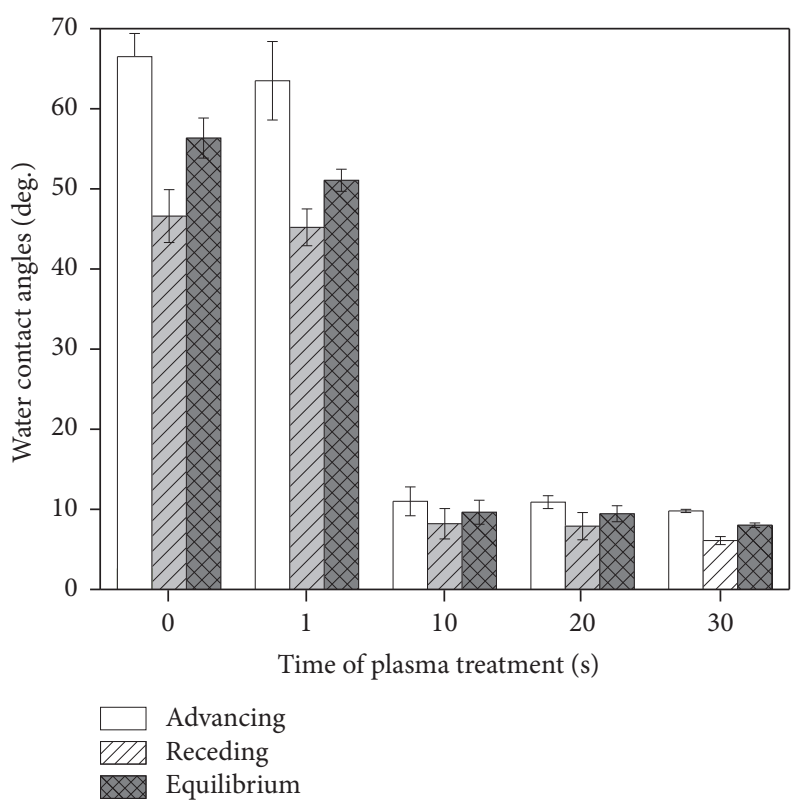

FIGURE 2: Advancing and receding water contact angles measured on the paper composite surface.

2.6. Surface Topography. Using optical profilometer (Contour GT, Veeco) images of the untreated and $30 \mathrm{~s}$ treated samples which were selected as examples were obtained, and the surfaces roughness was analyzed.

2.7. XPS (X-Ray Photoelectron Spectroscopy) Analysis. XPS spectra were taken by a multichamber UHV analytical system Prevac which is designed to test the surface properties of solids and powdered solids, in a wide range of temperature and pressure. Photoelectron spectroscopy (XPS) of the induced monochromatic (source MX-650's Gammadata Scienta, Al-K $\alpha$ anode) or achromatic X-rays (anode: $\mathrm{Mg} / \mathrm{Al}$ or Ag) was used.

\section{Results and Discussion}

The resulting FT-IR spectrum was compared with the spectra from the Library Hummel Polymer Sample; the best fit was obtained for the unsaturated polyester resin (Figure 1(b)) and it was $70.27 \%$.

As can be seen in Figure 2 the water contact angle for the untreated sample was $66.5 \pm 2.9^{\circ}$; when the sample was activated by plasma for only one second contact angle was decreased to $63.5 \pm 1.9^{\circ}$. Therefore, one can conclude that one-second activation is not enough to enhance adhesive properties of the paper surface. Then the sample was activated for 10 seconds and water contact angle was $11.0 \pm 1.8^{\circ}$. Additionally, increasing the time of the activation more than $10 \mathrm{~s}$ did not change the contact angle significantly. Thus, 20 - and 30-second activation resulted in the contact angle of $10.8 \pm 0.8^{\circ}$ and $9.8 \pm 0.2^{\circ}$, respectively. However, formamide (Figure 3) contact angle decreased more after one-second plasma activation in comparison to the water 


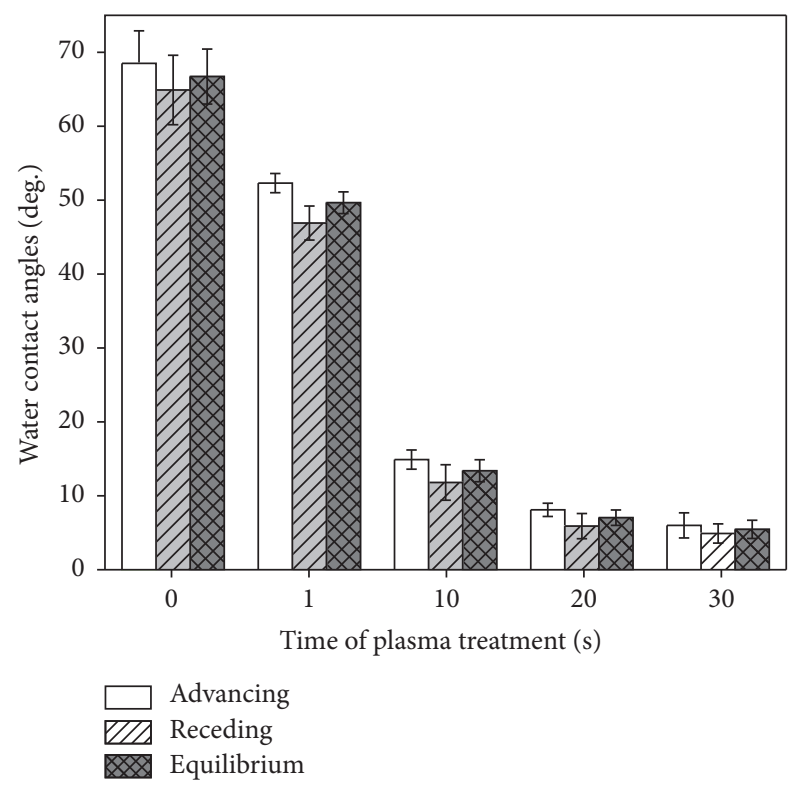

FIGURE 3: Advancing and receding formamide contact angles measured on the paper composite surface.

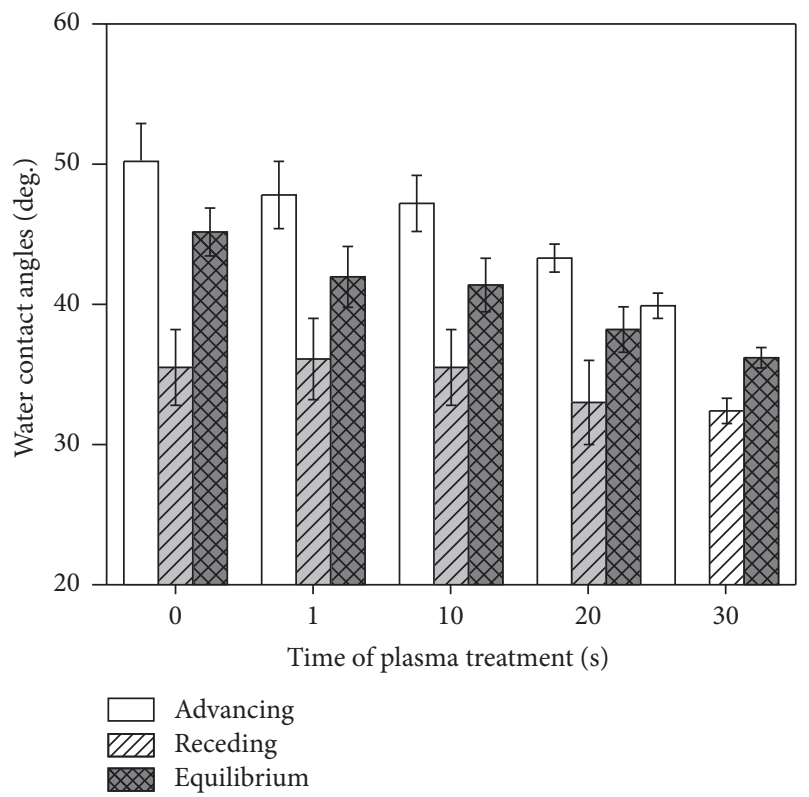

FIGURE 4: Advancing and receding diiodomethane contact angles measured on the paper composite surface.

contact angle. In this case the difference between the measured contact angle on the untreated and treated samples was about $30^{\circ}$. Longer plasma activation leads to further decrease of the formamide contact angle but as can be seen in Figure 4 the difference is not so high in comparison to the nonactivated and one-second activated plates. In the case of diiodomethane (Figure 4) the contact angles on the unmodified and $30 \mathrm{~s}$ plasma treated samples do not change so much in comparison to water and formamide contact angles, with the decreases being about $5^{\circ}$. Equilibrium contact

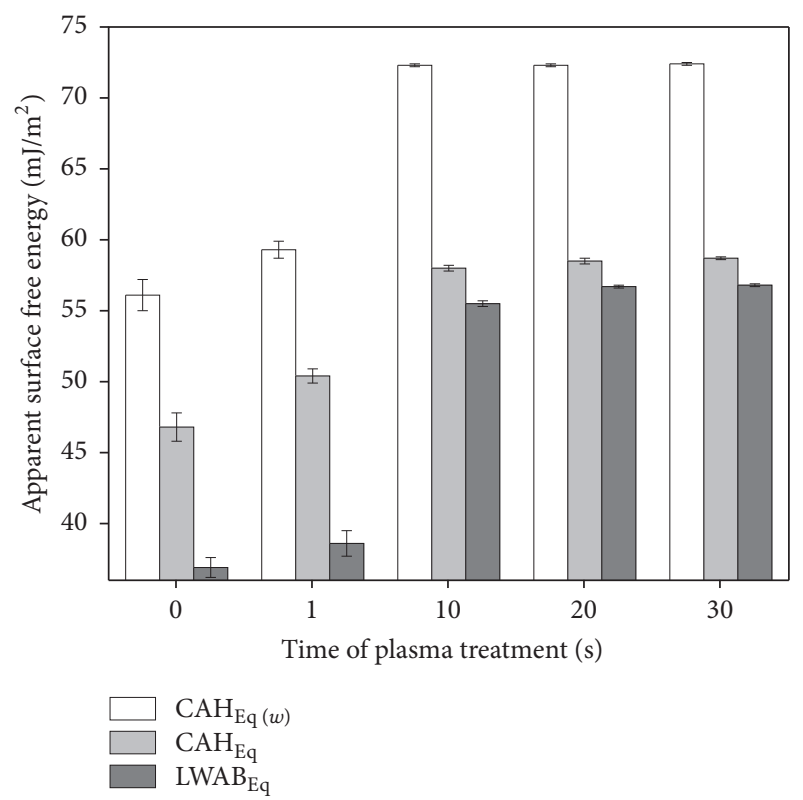

FIGURE 5: Total value of apparent surface free energy calculated from the $\mathrm{CAH}$ and LWAB approaches.

angles are always between advancing and receding contact angles. Calculation of this contact angle is important in case of high contact angle hysteresis (Figures 2-4). The total value of apparent surface free energy (Figure 5) was calculated from the hysteresis approach $(\mathrm{CAH})$ proposed by Chibowski [24-26] and for comparison from the Van Oss et al. [2123] approach using only equilibrium contact angles. For the unmodified sample the apparent surface free energy is $46.8 \pm$ $1.0 \mathrm{~mJ} / \mathrm{m}^{2}$ if calculated from the CAH approach, and it is $36.9 \pm 0.7 \mathrm{~mJ} / \mathrm{m}^{2}$ as calculated from the LWAB approach. The difference between these values is due to the fact that in the LWAB approach from calculation in this case negative value of electron acceptor parameter was obtained and total value of energy has been limited only to dispersive component. Moreover, in Figures 2-4, it is displayed that the hysteresis is especially high for the unmodified samples. This high value of hysteresis can result from the original commercial sample used. The material was taken straight from the production line and it might be chemically heterogeneous. Plasma treatment causes formation of new functional groups also increasing the roughness (Table 1), but the material unifies chemically by changing the thin surface layer. In the case of the plasma modified samples the energy value increases. The increase is more evident if the LWAB approach is considered. After the first second of modification the energy increases to $38.6 \pm 0.9 \mathrm{~mJ} / \mathrm{m}^{2}$; however, value is still limited to dispersive component. More promising are values calculated using $\mathrm{CAH}$ approach; using $\mathrm{CAH}$ approach the energy was presented as an average between energies calculated from equilibrium contact angles of tested liquids; for $1 \mathrm{~s}$ activation the energy was $50.4 \pm 0.5 \mathrm{~mJ} / \mathrm{m}^{2}$ and it is about $4 \mathrm{~mJ} / \mathrm{m}^{2}$ higher than for untreated one. Such increase is however too small from the technological point of view, but 10 seconds of plasma treatment causes the energy to increase to $55.5 \pm 0.2 \mathrm{~mJ} / \mathrm{m}^{2}$. 
TABLE 1: Roughness parameters for the tested surfaces.

\begin{tabular}{lccc}
\hline Sample name & $R_{a}[\mathrm{~nm}]$ & $R_{q}[\mathrm{~nm}]$ & $R_{t}[\mu \mathrm{m}]$ \\
\hline Untreated sample & $258.5 \pm 49.5$ & $321.1 \pm 59.2$ & $5.6 \pm 1.5$ \\
Plasma treated sample & $611.9 \pm 19.0$ & $743.7 \pm 38.1$ & $6.4 \pm 0.1$ \\
\hline
\end{tabular}

$R_{a}$ : average roughness, $R_{q}$ : quadratic mean of the surface roughness, and $R_{t}$ : maximum roughness height.

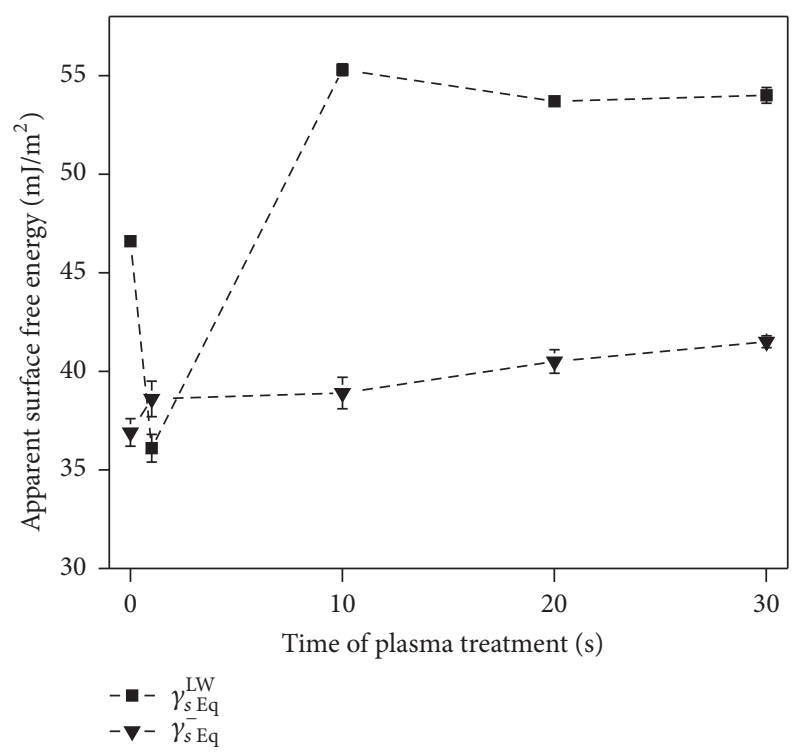

FIGURE 6: Dispersive $\gamma_{s}^{\mathrm{LW}}$ and electron donor $\gamma_{s}^{-}$components of apparent surface free energy calculated from the LWAB approach.

Longer plasma treatment does not induce significant changes in wettability and apparent surface free energy. Therefore, the optimal time of plasma treatment for these surfaces is between 1 and $10 \mathrm{~s}$. In technology of paper boxes the production of 10-second plasma modification can be too long but possible. This is conditioned by the length of the plasma strip mounted to the production line. Interesting data can be obtained using only calculated equilibrium water contact angles and $\mathrm{CAH}$ approach after 10-second activation energy increasing to $72.3 \mathrm{~mJ} / \mathrm{m}^{2}$; it results from water properties which interact with the surface in both dispersive $21.8 \mathrm{~mJ} / \mathrm{m}^{2}$ and polar $51 \mathrm{~mJ} / \mathrm{m}^{2}$.

As can be seen in Figure 6 plasma treatment largely influences changes of electron donor parameter of apparent surface free energy. This parameter changes from $46.6 \pm$ $0.1 \mathrm{~mJ} / \mathrm{m}^{2}$ for the untreated sample to $55.3 \pm 0.3 \mathrm{~mJ} / \mathrm{m}^{2}$ for the sample activated for $10 \mathrm{~s}$ by atmospheric plasma. Longer plasma activation does not change this parameter significantly. It is very interesting that the dispersive component increases slightly with the plasma treatment lengthening, which for the untreated sample is $36.9 \pm 0.7 \mathrm{~mJ} / \mathrm{m}^{2}$ to about $40 \mathrm{~mJ} / \mathrm{m}^{2}$ for the treated one. This increase may not be of great importance in practical application, but if this effect is added to the increasing electron donor parameter and increasing roughness of the surface, it can help in gluing this material in production of packaging and with printing on these materials. Changes of surface properties can be also
TABLE 2: The contents of elements on the surface from XPS for the untreated and plasma treated samples.

\begin{tabular}{lccc}
\hline & Name & \% at cont. & \% mass cont. \\
\hline \multirow{3}{*}{ Untreated sample } & C 1s & 75.3 & 69.8 \\
& O 1s & 23.2 & 28.6 \\
& N 1s & 1.5 & 1.6 \\
\hline \multirow{3}{*}{ Plasma treated sample } & C 1s & 69.2 & 63.0 \\
& O 1s & 28.7 & 34.7 \\
& N 1s & 2.2 & 2.3 \\
\hline
\end{tabular}

seen in the changes of topography; the results in Table 1 and Figure 7 show that the tested surface is rough. The untreated sample is rough on the nanoscale where the average roughness is $258.5 \pm 49.5 \mathrm{~nm}$. The same surface after the plasma treatment becomes about three times rougher and its average roughness increases to about $611.9 \pm 19.0 \mathrm{~nm}$. Kan and Yuen [27] used low temperature plasma for activation of polyester which is used in the textile industry to improve antistatic property of the polyester fabric. They used radiofrequency plasma and oxygen as the plasma gas. From SEM microscopy they clearly demonstrated that untreated polyester had a smoother surface on which after the plasma treatment there were drastic changes in the fiber morphology with the presence of voids and pores. An increase in roughness of our samples also took place (Table 1). Using the XPS technique in [27] it was found that on the surface oxygen amount increases but carbon amount decreases. The percentage of oxygen and carbon is very similar to that found for our samples (Table 2). Obviously after the plasma treatment the amounts of these elements differ because of different kinds of plasma used for surface activation. After activation, with the plasma reducing the amount of carbon it can be seen from the XPS that it was detached from the surface $\mathrm{CH}_{3}$ group which is evident from the reduced amount of $\mathrm{C}-\mathrm{C}$ bonds. As a result, the plasma will also become detached (Table 3 ) from the hydrogens of the $\mathrm{CH}$ groups of a certain amount. Also a slight decrease in the content of carbon in the form of the C-O-C while increasing its presence in the form of a group $\mathrm{O}=\mathrm{C}-\mathrm{O}-$ may be indicative of detachment of the carbon of the C-O-C as $\mathrm{CH}_{2}$. The test material is a polymer production and therefore present on the surface of the additional moiety such as $\mathrm{C}-\mathrm{OH}$ groups or a small amount of nitrogen; the presence of these groups does not result from the construction of the polymer. During activation of the plasma on the surface energy balance is disturbed and therefore they easily attach themselves to the different kinds of functional groups. The gas used to activate the air which is composed of nitrogen, oxygen, and other elements contains substantial amounts of water vapor. Accordingly, the amount of oxygen of the surface increases as the $\mathrm{C}=\mathrm{O}$ group and by the additional effect of water vapor as well as $\mathrm{OH}$ groups. It can be also seen that the number of groups containing nitrogen increases.

Zao et al. [14] stated that during the time of plasma treatment the polymer chains reacted and produced surface hydroxyl, oxide, and nitride hydrophilic moieties on the surface. This suggestion is confirmed in our experiment by 


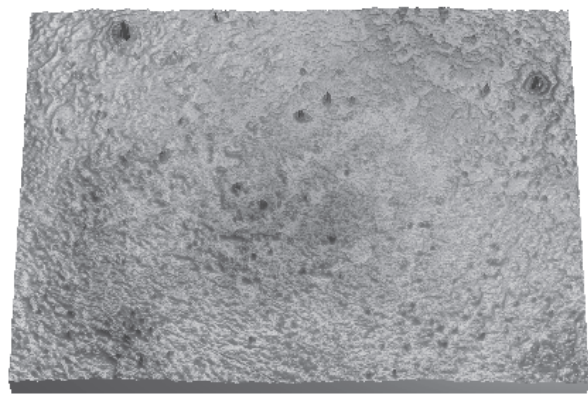

(a)

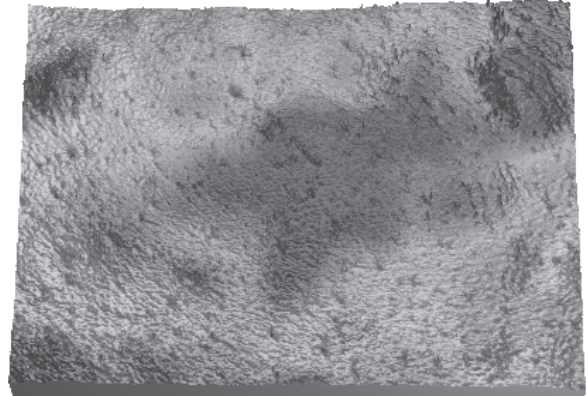

(b)

FiguRE 7: Surface topography of (a) untreated sample and (b) plasma treated (size of image $1.3 \times 0.94 \mathrm{~mm}$ ).

TABLE 3: The centration of functional groups on the surface from XPS for the untreated and plasma treated samples.

\begin{tabular}{|c|c|c|c|}
\hline & Name & $\%$ at cont. & Group \\
\hline \multirow{9}{*}{ Untreated sample } & C 1s A & 61.1 & $\mathrm{C}-\mathrm{C}, \mathrm{C}-\mathrm{H}$ \\
\hline & C 1s B & 27.8 & $\mathrm{C}-\mathrm{O}-\mathrm{C}, \mathrm{C}-\mathrm{OH}, \mathrm{C}-\mathrm{N}$ \\
\hline & $\mathrm{C}$ 1s C & 3.4 & $\mathrm{C}=\mathrm{O}$ \\
\hline & C 1s D & 7.7 & $\mathrm{O}=\mathrm{C}-\mathrm{O}=$ \\
\hline & O ls A & 13.7 & $\mathrm{C}=\mathrm{O}$ \\
\hline & O 1s B & 59.3 & $\mathrm{C}-\mathrm{OH}$ \\
\hline & $\mathrm{O}$ 1s C & 27.0 & $\mathrm{O}=\mathrm{C}-\mathrm{O}-$ \\
\hline & $\mathrm{N}$ 1s A & 91.0 & Amine \\
\hline & $\mathrm{N}$ 1s B & 9.0 & $\mathrm{~N}-\mathrm{O}$ \\
\hline \multirow{10}{*}{ Sample treated with plasma } & C 1s A & 57.1 & $\mathrm{C}-\mathrm{C}, \mathrm{C}-\mathrm{H}$ \\
\hline & C 1s B & 25.9 & $\mathrm{C}-\mathrm{O}-\mathrm{C}, \mathrm{C}-\mathrm{OH}, \mathrm{C}-\mathrm{N}$ \\
\hline & $\mathrm{C}$ 1s C & 7.2 & $\mathrm{C}=\mathrm{O}$ \\
\hline & C 1s D & 9.7 & $\mathrm{O}=\mathrm{C}-\mathrm{O}=$ \\
\hline & O 1s A & 18.4 & $\mathrm{C}=\mathrm{O}$ \\
\hline & O 1s B & 55.8 & $\mathrm{C}-\mathrm{OH}$ \\
\hline & $\mathrm{O}$ 1s C & 25.8 & $\mathrm{O}=\mathrm{C}-\mathrm{O}-$ \\
\hline & $\mathrm{N}$ 1s A & 14.6 & Imine \\
\hline & $\mathrm{N}$ 1s B & 66.8 & Amine \\
\hline & $\mathrm{N}$ 1s C & 18.6 & $\mathrm{~N}-\mathrm{O}$ \\
\hline
\end{tabular}

XPS (Table 2) data. They also found that the main reason the mechanism of the surface properties changed was due to the breaking of $\mathrm{C}-\mathrm{H}$ and $\mathrm{C}-\mathrm{C}$ bonds. The aliphatic chains broke as well in the pendent $\mathrm{CHx}$ groups through the formation of free radicals and new chemical groups appearing within the reaction of the plasma gases. In the same paper they also measured the influence of the distance between the substrate and the plasma flame, which was 2,3 , and $4 \mathrm{~mm}$. The change in the distance in this range did not affect significantly the apparent surface free energy especially in the case of longer time activation. Influence of the power on the apparent surface free energy was also evaluated. The polyester plates were activated for $0.5 \mathrm{~s}$ and $1.5 \mathrm{~s}$ with the power of 40 to 180 Watt. In both cases the energy increased to the power 80 Watt and then stabilized.

The main propose of the manuscript was to improve gluing of these surfaces. Because of that there were prepared $5 \mathrm{~cm} \times 0.5 \mathrm{~cm}$ strips from the tested materials. Some of the strips were activated by air plasma for $30 \mathrm{~s}$ seconds. In the first test, the untreated strips were stuck together by the Jowat glue (normally used for paper), and one of them (Figure 8) was suspended from the handle while the other was attached to the second strip dynamometer. The next step was applying a force to the dynamometer. The weld of the untreated strips was torn at $0.6 \mathrm{~N}$. In the second step the plasma treated sample was glued with the untreated sample and torn at the highest value possible in the apparatus which was $1 \mathrm{~N}$. This force is sufficient in the case of production.

Verma et al. [28] used the waterborne polyester resin as an anticorrosion hydrophobic coating on copper. The water contact angle measured on the copper plate covered with the polyester layer was $56^{\circ}$ and the average roughness was about 2-3 nm. Smith and Pitrola [29] described the acidbase characterization of four polyesters surfaces by polyester solution casting against a number of substrates: aluminium, glass, mica, poly(ethylene terephthalate) (PET), Teflon, and 


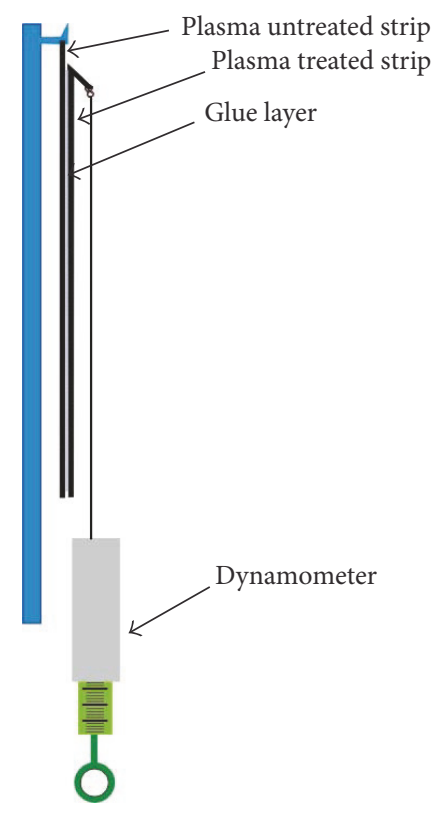

FIGURE 8: Method of testing the strength of the weld.

dry nitrogen gas. After drying the polymer film it was carefully removed from the substrate, and then contact angles were measured. The obtained results show that the work of adhesion between the particular polyester surface and acidic or basic liquid is dependent on the casting substrate and aging time of the polyester surface. The initial acidic or basic character of the polyester surface (substrate side) is strongly affected by the acid/base surface properties. Lin et al. [30] investigated corrosion protection of painted cold rolled steel by low temperature plasma polymerization. The thermosetting powder coating type was used for spraying the steel surface. The paint was composed of polyester, epoxy resin, and pigment. The apparent surface free energy of the painted unmodified steel was $79.8 \mathrm{~mJ} / \mathrm{m}^{2}$; for the control phosphated steel with paint $75.1 \mathrm{~mJ} / \mathrm{m}^{2}$ and for the $\mathrm{Ar}-\mathrm{H}_{2}$ plasma cleaned with paint it was $70.9 \mathrm{~mJ} / \mathrm{m}^{2}$. In that case the main component of energy was a dispersive parameter.

Taking into account the studies by Zhao et al. [14] the energy on the bare polyester surface is about $40 \mathrm{~mJ} / \mathrm{m}^{2}$; it is calculated from (3). In our study for the composite polyesterpaper material, the energy is $34.2 \pm 1.3 \mathrm{~mJ} / \mathrm{m}^{2}$, and for the steel surface covered by the polyester paint it is about $70 \mathrm{~mJ} / \mathrm{m}^{2}$ [30]. For the copper plate covered by a thin layer of polyester [27] it was about $56 \mathrm{~mJ} / \mathrm{m}^{2}$. Comparing this with the research by Smith and Pitrola [29] it can be suggested that a thin layer of polystyrene does not screen completely the energy originating from the matrix. However, hydrophobic or hydrophilic surface properties are determined not only by the surface chemical composition but also by the surface roughness.

\section{Conclusion}

Air plasma activation for the composite paper materials can improve gluing of these materials. Moreover, due to a great reduction of prices the equipment of the surface plasma treatment can find practical application in printing industry in the near future.

The contact angles of polar liquids (water and formamide) decrease on the surfaces treated by air plasma. These liquids have polarized covalent bonds of their molecules and the ability to form hydrogen bonds. Diiodomethane interacts with the surface by dispersive force only and hence the changes in its contact angle are smaller, and the changing of the surface topography plays a major role here. The apparent surface free energy decreases with duration of plasma treatment, which is favourable for the printing industry because if the surface has a higher value of energy, the offset ink adheres stronger to such a surface. The energy values calculated from the CAH and LWAB approaches differ slightly but the tendency of the change is the same. In industry the application of the CAH approach seems to be more justified because apparent surface free energy can be estimated much more readily using only one liquid. One should keep in mind that in industry the knowledge of the energy changes may be significant. Wettability changes are due to the formation of new surface polar groups which was found by the XPS technique. The capacity of this type of surface bonding can be improved by combination of created polar groups and increasing roughness.

\section{Conflicts of Interest}

The author declares no conflicts of interest.

\section{References}

[1] P. Frisk, A. Lindvall, R. Hudecek, and U. Lindh, "Decrease of trace elements in erythrocytes and plasma after removal of dental amalgam and other metal alloys," Biological Trace Element Research, vol. 113, no. 3, pp. 247-259, 2006.

[2] H.-S. Kim, W. S. Kang, G.-H. Kim, and S. H. Hong, "Metal surface oxidation by using dielectric barrier discharge," Thin Solid Films, vol. 518, no. 22, pp. 6394-6398, 2010.

[3] D. H. Shin, C. U. Bang, J. H. Kim et al., "Modification of metal surfaces by microwave plasma at atmospheric pressure," Surface and Coatings Technology, vol. 201, no. 9-11, pp. 4939-4942, 2007.

[4] G.-Q. Ma, J.-J. Zhai, B. Liu, D.-H. Huang, and J. Sheng, "Plasma modification of polypropylene surfaces and grafting copolymerization of styrene onto polypropylene," Chinese Journal of Polymer Science (English Edition), vol. 30, no. 3, pp. 423-435, 2012.

[5] D. Hegemann, H. Brunner, and C. Oehr, "Plasma treatment of polymers to generate stable, hydrophobic surfaces," Plasmas and Polymers, vol. 6, no. 4, pp. 221-235, 2001.

[6] M. Šíra, P. St’ahel, V. Buršíková, J. Vohánka, and D. Trunec, "Activation of polyethylene and polypropylene in atmospheric pressure glow discharge," Czechoslovak Journal of Physics, vol. 54, no. 3, pp. C835-C839, 2004.

[7] I. Aydin and C. Demirkir, "Activation of spruce wood surfaces by plasma treatment after long terms of natural Surface inactivation," Plasma Chemistry and Plasma Processing, vol. 30, no. 5, pp. 697-706, 2010. 
[8] G. Avramidis, L. Klarhöfer, W. Maus-Friedrichs, H. Militz, and W. Viöl, "Influence of air plasma treatment at atmospheric pressure on wood extractives," Polymer Degradation and Stability, vol. 97, no. 3, pp. 469-471, 2012.

[9] Y. Liu, Y. Tao, X. Lv, Y. Zhang, and M. Di, "Study on the surface properties of wood/polyethylene composites treated under plasma," Applied Surface Science, vol. 257, no. 3, pp. 11121118, 2010.

[10] T. S. Williams, H. Yu, and R. F. Hicks, "Atmospheric pressure plasma activation of polymers and composites for adhesive bonding: a critical review," Reviews of Adhesion and Adhesives, vol. 1, no. 1, pp. 46-87, 2013.

[11] R. Tadmor, R. Das, S. Gulec et al., "Solid-liquid work of adhesion," Langmuir, vol. 33, pp. 3594-3600, 2017.

[12] J. Molina, J. Fernández, M. Fernandes et al., "Plasma treatment of polyester fabrics to increase the adhesion of reduced graphene oxide," Synthetic Metals, vol. 202, pp. 110-122, 2015.

[13] A. B. D. Cassie and S. Baxter, "Wettability of porous surfaces," Transactions of the Faraday Society, vol. 40, pp. 546-551, 1944.

[14] Y. Zhao, S. Tang, S.-W. Myung, N. Lu, and H.-S. Choi, "Effect of washing on surface free energy of polystyrene plate treated by RF atmospheric pressure plasma," Polymer Testing, vol. 25, no. 3, pp. 327-332, 2006.

[15] L. Holysz, K. Terpilowski, V. Zarko, and E. Chibowski, "Superhydrophobic polystyrene layers filled with silica on glass," Surface Innovations, vol. 1, no. 1, pp. 52-59, 2013.

[16] K. Terpilowski, D. Rymuszka, L. Hołysz, and M. Ilnicki, "Surface properties of metal alloys used in aviation after plasma treatment," Surface and Interface Analysis, 2017.

[17] R. Tadmor, "Line energy and the relation between advancing, receding, and Young contact angles," Langmuir, vol. 20, no. 18, pp. 7659-7664, 2004.

[18] R. Tadmor and P. S. Yadav, "As-placed contact angles for sessile drops," Journal of Colloid and Interface Science, vol. 317, no. 1, pp. 241-246, 2008.

[19] R. Tadmor, "Line energy, line tension and drop size," Surface Science, vol. 602, no. 14, pp. L108-L111, 2008.

[20] K. Terpilowski, "Surface free energy of superhydrophobic materials obtained by deposition of polymeric particles on glass," Advances in Contact Angle, Wettability and Adhesion, vol. 2, pp. 381-395, 2015.

[21] C. J. Van Oss, M. J. Roberts, R. J. Good, and M. K. Chaudhury, "Determination of the apolar component of the surface tension of water by contact angle measurements on gels," Colloids and Surfaces, vol. 23, no. 4, pp. 369-373, 1987.

[22] C. J. Van Oss, M. K. Chaudhury, and R. J. Good, "Interfacial Lifshitz-van der Waals and polar interactions in macroscopic systems," Chemical Reviews, vol. 88, no. 6, pp. 927-941, 1988.

[23] C. J. Van Oss, L. Ju, M. K. Chaudhury, and R. J. Good, "Estimation of the polar parameters of the surface tension of liquids by contact angle measurements on gels," Journal of Colloid And Interface Science, vol. 128, no. 2, pp. 313-319, 1989.

[24] E. Chibowski, "Contact angle hysteresis due to film present behind the drop," Contact Angle, Wettability and Adhesion, vol. 2, pp. 265-288, 2002.

[25] E. J. Chibowski, "Surface free energy and wettability of silyl layers on silicon determined from contact angle hysteresis," Advances in Colloid and Interface Science, vol. 113, no. 2-3, pp. 121-131, 2005.

[26] E. Chibowski and K. Terpiłowski, "Comparison of apparent surface free energy of some solids determined by different approaches," Contact Angle, Wettability and Adhesion, vol. 6, pp. 283-299, 2009.

[27] C. W. Kan and C. W. M. Yuen, "Static properties and moisture content properties of polyester fabrics modified by plasma treatment and chemical finishing," Nuclear Instruments and Methods in Physics Research. B, vol. 266, no. 1, pp. 127-132, 2008.

[28] G. Verma, S. K. Dhoke, and A. S. Khanna, "Polyester basedsiloxane modified waterborne anticorrosive hydrophobic coating on copper," Surface and Coatings Technology, vol. 212, pp. 101-108, 2012.

[29] R. Smith and R. Pitrola, "Influence of casting substrate on the acid-base interaction energies of various polyesters," Polymer, vol. 41, no. 26, pp. 9111-9122, 2000.

[30] Y.-S. Lin, C.-H. Chang, and T.-J. Huang, "A study of the low temperature plasma polymerization on enhancing interface of painted cold rolled steel in salt bath," Surface and Coatings Technology, vol. 200, no. 10, pp. 3355-3365, 2006. 

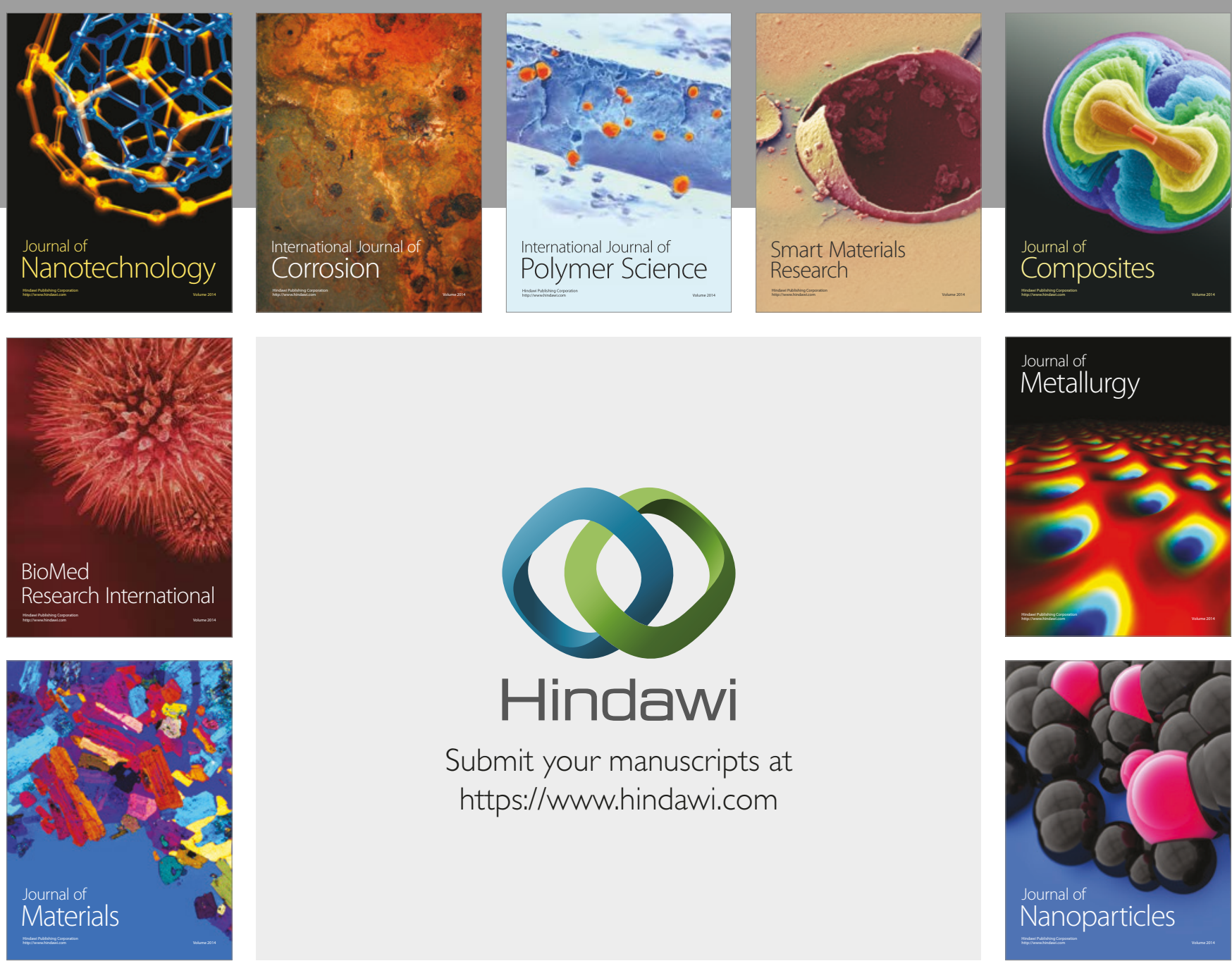

\section{Hindawi}

Submit your manuscripts at

https://www.hindawi.com
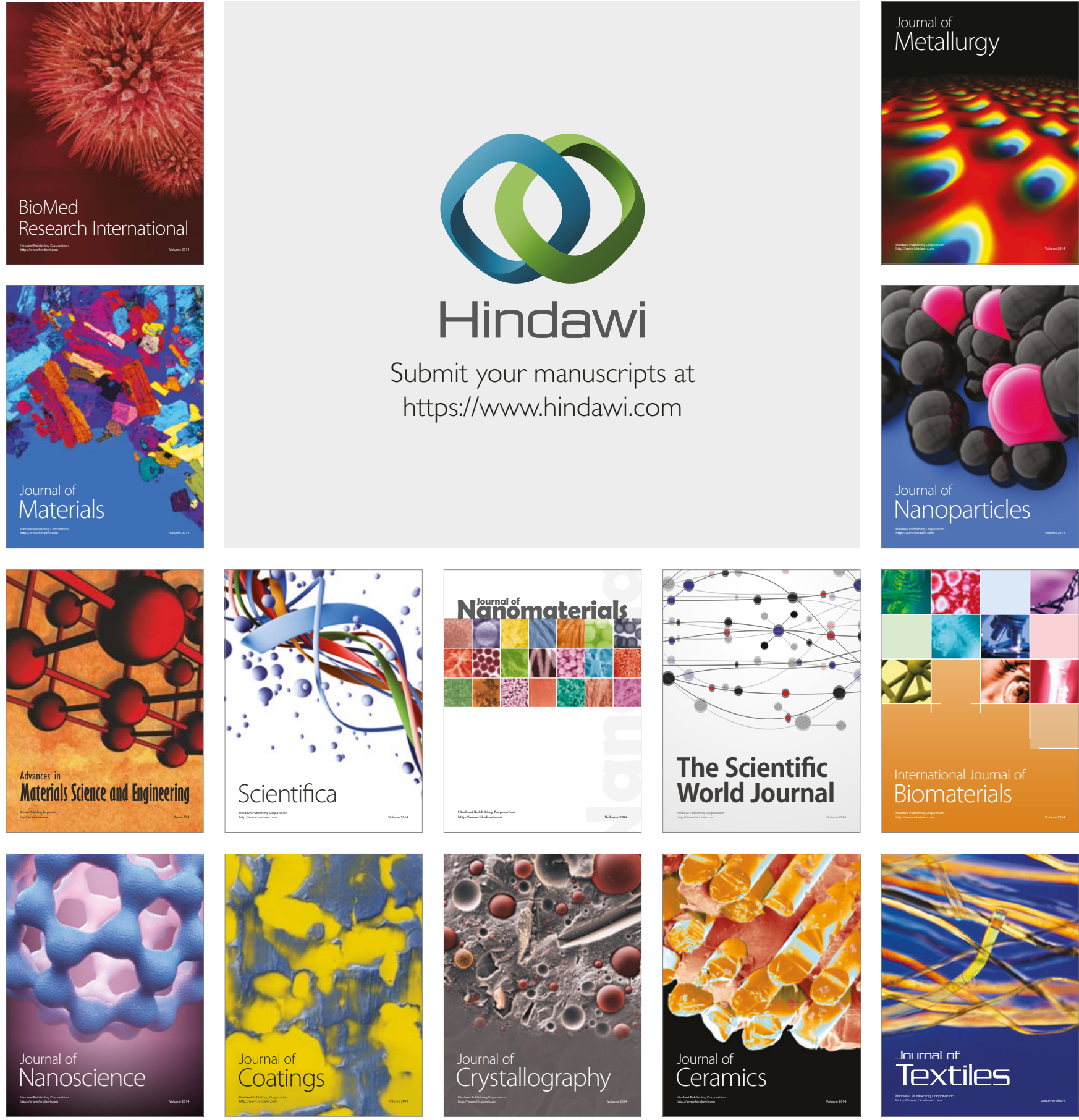

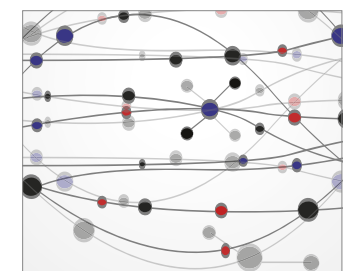

The Scientific World Journal
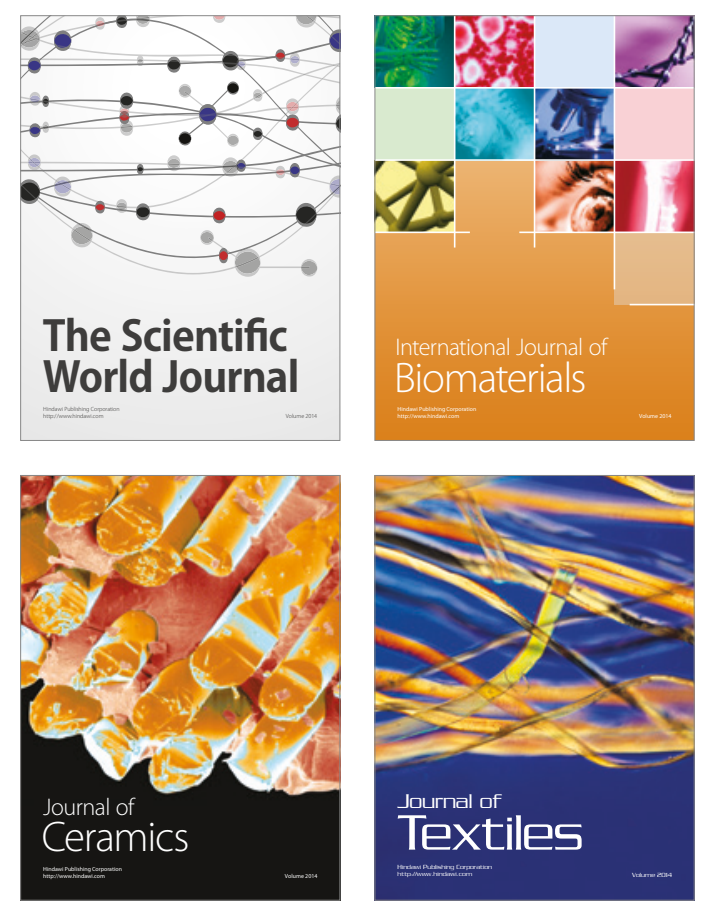